\title{
Avaliação da qualidade de formulações farmacêuticas contendo sulfato ferroso, dispensadas na rede pública de saúde
}

\author{
Evaluation of the quality of pharmaceutical formulations \\ containing ferrous sulfate supplied in the public health system
}

Recebido em: 23/05/2016

Aceito em: 23/06/2016
Helena Miyoco YANO; Cibele Nicolaski PEDRON; Valéria Adriana Pereira MARTINS; Fernanda Fernandes FARIAS; Luz Marina TRUJILLO; Nelson Aranha DIAS Instituto Adolfo Lutz. Centro de Medicamentos, Cosméticos e Saneantes. Av. Dr Arnaldo, 355-Cerqueira César, São Paulo, SP. CEP 01246-902, Brasil. E-mail:heleyano@ig.com.br

\begin{abstract}
For the control and prevention of temporary anemia of iron in the population, it is recommended to follow a proper supplementation, in which ferrous sulfate is the main drug of choice in these cases. Considering that this medicine is distributed by the government mainly to public hospitals and Basic Health Units, it becomes necessary to analyze for quality assessment in their many pharmaceutical forms. It was established between the Adolfo Lutz Institute and the Health Surveillance of São Paulo, the Program Quality Drug Monitoring to ensure the quality, safety, and efficacy of medicine. The aim of the present study was to analyze ferrous sulfate in oral solution, syrup, and tablet and evaluate the results to detect their impact on public health. The presentations were analyzed according to pharmacopoeial monographs concerning the analysis of aspect, determination of weight/volume $/ \mathrm{pH}$, identification of ferrous sulfate and its content, and the labeling analysis was performed, by current legislation. The obtained analysis results from the Program for Quality Control of Drugs and techniques complaints in the period $2008-2014$ were: $57 \%$ as satisfactory, and $43 \%$ unsatisfactory. Among the unsatisfactory, $7 \%$ were related to labeling analysis, $18 \%$ to aspect and $18 \%$ related to sulfate ferrous assay. It is of great importance for public health, the continuity of these Programs for Drug Quality Control to ensure the maintenance of Good Manufacturing Practices (GMP) to protect and promote the health of the population.
\end{abstract}

Keywords: medicines, health surveillance, anemia, quality control.

\section{RESUMO}

Para o controle e prevenção da anemia temporária de ferro na população, é recomendado seguir uma suplementação adequada, sendo o sulfato ferroso o principal fármaco de escolha. Considerando que este medicamento é distribuído pelo governo, principalmente para hospitais públicos e Unidades Básicas de Saúde (UBS), torna-se necessária a análise para verificação da qualidade em suas diversas formas farmacêuticas. Foi estabelecido entre o Instituto Adolfo Lutz e a Vigilância Sanitária de São Paulo, o Programa de Monitoramento de Qualidade de Medicamentos, como meio de garantir a qualidade, segurança e eficácia do medicamento. O objetivo do presente trabalho foi analisar sulfato ferroso em solução oral, xarope e comprimido e avaliar os resultados para detectar o impacto destes na saúde pública. As apresentações foram analisadas de acordo com monografias farmacopeicas quanto aos ensaios de aspecto, determinação de peso/volume/pH, identificação e teor de sulfato ferroso, e quanto à análise de rotulagem foi realizada de acordo com a legislação vigente. Os resultados das análises obtidas do Programa de Controle de Qualidade de Medicamentos e de queixas técnicas, no período de 2008-2014, foram: 57\% considerados satisfatórios, e 43\% insatisfatórios. Dentre os insatisfatórios, 7\% estavam relacionados à análise de rotulagem, $18 \%$ ao aspecto e $18 \%$ relacionados ao ensaio de teor de sulfato ferroso. É de grande importância para a saúde pública, a continuidade destes programas de controle de qualidade de medicamentos, para que se assegure a manutenção de Boas Práticas de Fabricação (BPF), a fim de proteger e promover a saúde da população.

Palavras-chave: medicamentos, vigilância sanitária, anemia, controle de qualidade 


\section{INTRODUÇÃO}

Os medicamentos representam um elemento com características particulares e especiais dentro da medicina, haja visto seu papel como parte integrante da Assistência Farmacêutica, tendo como finalidade diagnosticar, prevenir, curar ou aliviar sintomas de doenças. Com a publicação da Portaria GM no 3916/98, foi estabelecida a Política Nacional de Medicamentos com propósito de garantir a segurança, a eficácia, e a qualidade destes produtos, a promoção do uso racional e o acesso da população àqueles considerados essenciais. Entre as principais diretrizes estão a reorientação da assistência farmacêutica e o estabelecimento da relação de medicamentos essenciais (1-2).

Como parte integrante da Política Nacional de Saúde, foi estabelecida a Política Nacional de Assistência Farmacêutica (PNAF), formada por um conjunto de ações voltadas à promoção, proteção e recuperação da saúde de modo a garantir os princípios da universalidade, integralidade e equidade (3).

Os medicamentos essenciais, segundo a Organização Mundial da Saúde (OMS), satisfazem as necessidades de atenção à saúde da maioria da população. Estes são selecionados de acordo com sua relevância em saúde pública, considerando o custo-benefício. Devem estar disponíveis nos sistemas de saúde, em quantidades suficientes, nas formas farmacêuticas apropriadas, com qualidade garantida, informações adequadas e, a preços acessíveis aos pacientes e à comunidade (4).

No Brasil, o Ministério da Saúde é responsável pela publicação da Relação Nacional de Medicamentos (RENAME), que lista os medicamentos essenciais para tratar as doenças mais comuns na população. Baseado nesta lista, os estados e municípios constroem sua própria relação de medicamentos (5).

O sulfato ferroso heptaidratado é um importante medicamento para o tratamento da anemia, que consta sob a forma de comprimido e de solução oral na RENAME(5).

Segundo a OMS, dois bilhões de pessoas (mais de $30 \%$ da população mundial) são anêmicas, principalmente devido à deficiência de ferro. Nos países em desenvolvimento, a anemia é agravada pela malária e verminoses, dificultando ainda mais a situação, uma vez que são doenças negligenciadas (6).

A anemia é definida como uma redução na concentração de hemoglobina no sangue, sendo a ferropriva ou ferropênica causada por uma série de fatores: ingestão insuficiente de ferro na dieta, alteração da absorção intestinal ou do transporte plasmático, sangramentos intensos, aumento da demanda do ferro (gravidez). Para este tratamento, o principal medicamento é o sal de ferro disponível no mercado na forma de sulfato ferroso, em apresentações como drágea, comprimidos, gotas, xaropes e solução injetável. Geralmente administrado por via oral, porém em casos especiais, pode ser administrado por via parenteral (6-7).

Todo ferro provém da dieta, mas o organismo o aproveita geralmente em estado ferroso, sendo que no estado férrico é absorvido de maneira limitada. O estoque geral de ferro no organismo é cerca de 4,0 g, de modo que aproximadamente $65 \%$ estão contidos na hemoglobina em estado ferroso $\left(\mathrm{Fe}^{2+}\right)$ (7).

A determinação analítica de sulfato ferroso pode ser realizada conforme monografias farmacopeicas, sendo que estão descritas como matéria-prima e na forma farmacêutica de comprimido nas Farmacopeias Britânica, 2012; Brasileira, 2010 e Americana, 2012; e nas formas de solução oral e xarope, na Farmacopeia Americana, 2012. Segundo estas monografias, o ensaio de doseamento deve ser realizado realizado por método volumétrico (titulação direta) (7-8-9).

Neste trabalho, para determinação de ferro nas amostras, foi também realizada a titulação potenciométrica de oxirredução, utilizando o equipamento titulador automático que identifica o ponto de equivalência por meio de eletrodo de platina. Esta técnica é aplicada tanto em laboratórios de controle da qualidade da indústria, quanto em órgãos oficiais e descritas em literaturas (10).

O Instituto Adolfo Lutz (IAL) é um Laboratório Nacional em Saúde Pública e Laboratório de Referência Macroregional pelo Ministério da Saúde, com sede em São Paulo. Colabora na produção de conhecimentos relevantes para a saúde coletiva. Deste modo, o Centro de Medicamentos, Cosméticos e Saneantes, integrante do IAL, tem estabelecido programas de monitoramento da qualidade em medicamentos distribuídos pelo Sistema Único de Saúde (SUS), integrado às demais ações de Vigilância Sanitária. Neste âmbito, desenvolve ações e pesquisas como neste presente trabalho, que teve como objetivo determinar sulfato ferroso em diferentes apresentações farmacêuticas, bem como verificar possíveis desvios da qualidade e avaliar os resultados, com intuito de contribuir na garantia de acesso, quanto à sua qualidade e segurança à população. 


\section{MATERIAIS E MÉTODOS}

Equipamentos: balança analítica Metller Toledo ${ }^{\circledR}$ modelo AL 204, potenciômetro Q-400M1 Quimis ${ }^{\circledR}$, titulador automático Metrohm ${ }^{\circledR}$ modelo 905 Titrando com os módulos 804 Ti Stand, 800 dosino, 854 iConect, 807 Dosing unit (bureta), 802 Stirrer (agitador em hélice), Pt-Titrode (eletrodo de platina) e software Tiamo 2.3.

Sais e reagentes: oxalato de sódio Dinâmica ${ }^{\circledR}$ pureza $99 \%$, ortofenantrolina $\operatorname{Vetec}^{\circledR}$, solução titulante de sulfato cérico $0,1 \mathrm{M}$ Haloquímica ${ }^{\circledR}$, ácido sulfúrico Dinâmica ${ }^{\circledR}$, ácido clorídrico Vetec ${ }^{\circledR}$, ácido nítrico Dinâmi$\mathrm{ca}^{\circledR}$, ferricianeto de potássio Synth ${ }^{\circledR}$, hidróxido de sódio Synth ${ }^{\circledR}$, cloreto de bário Dinâmica ${ }^{\circledR}$, acetato de chumbo Synth ${ }^{\circledR}$ e acetato de amônio Dinâmica ${ }^{\circledR}$.

Amostras: foram recebidas para análise, 28 amostras do medicamento sulfato ferroso heptaidratado pela Vigilância Sanitária através de Programa de Monitoramento da Qualidade de Medicamentos e de queixas técnicas de profissionais das Unidades Básicas da Saúde por dúvida da qualidade do medicamento, no período de 2008 a 2014.

As análises das amostras foram realizadas quanto aos ensaios farmacopeicos: aspecto, determinação de peso (para os comprimidos), determinação de volume (para as soluções orais), pH, identificação e teor de sulfato ferroso heptaidratado. Quanto à análise de rótulo foi verificado se os dizeres da rotulagem do produto estavam de acordo com as legislações vigentes (1) e se encontrava expresso como sulfato ferroso heptaidratado $\left(\mathrm{FeSO}_{4} \cdot 7 \mathrm{H}_{2} \mathrm{O}\right)$ e ferro elementar $(\mathrm{Fe})$ conforme farmacopeias (8-9).

A análise de aspecto consistiu em verificar as condições de recebimento das amostras: se os comprimidos estavam íntegros, quebradiços ou rachados, se a coloração estava uniforme, se o blister estava bem fechado, se a solução estava homogênea, e se os frascos estavam bem vedados ou com vazamento.

A determinação do peso dos comprimidos foi realizada pesando individualmente 20 unidades de comprimidos. Foi calculado o peso médio e a variação máxima e mínima, e os resultados obtidos foram avaliados de acordo com os critérios de determinação de peso da Farmacopeia Brasileira $5^{\mathrm{a}}$ Ed (FB5) (8).

A determinação de volume foi realizada em 10 unidades. Os rótulos dos frascos foram retirados e cada recipiente foi pesado individualmente. O conteúdo foi transferido para a determinação de massa. Os recipientes e as tampas foram lavados com água e secados à tempe- ratura ambiente. As tampas com seus respectivos frascos foram novamente pesados. A diferença entre as duas pesagens representou o peso do conteúdo. Os volumes individuais foram determonados por meio da densidade da solução. A densidade relativa foi realizada com auxílio de picnômetro. A calibração consiste na determinação da massa do picnômetro vazio e da massa de seu conteúdo com água, a $20^{\circ} \mathrm{C}$. A amostra foi transferida para o picnômetro com devido cuidado e em seguida o conjunto foi pesado. $\mathrm{O}$ peso da amostra correspondeu à diferença de massa de picnômetro cheio e vazio. A densidade relativa foi calculada determinando a razão entre a massa da amostra líquida e a massa da água. A densidade relativa foi utilizada para calcular a densidade da amostra.

A partir da densidade relativa obtida, o volume médio da amostra foi calculado. A avaliação do resultado foi realizada de acordo com a Farmacopeia Brasileira, 2010 (8).

A determinação de $\mathrm{pH}$ foi obtida por leitura direta em potenciômetro digital de acordo com a Farmacopeia Americana, 2012 (9).

Para as reações de identificação do sulfato ferroso heptaidratado foram utilizadas soluções reagentes de cloreto de bário, ácido clorídrico, ácido nítrico, acetato de chumbo, acetato de amônio, ferricianeto de potássio e hidróxido de sódio que consistiram na formação de precipitados característicos, de acordo com a FB5 (8).

$\mathrm{O}$ ensaio de teor de sulfato ferroso heptaidratado foi determinado por titulação direta (ensaio farmacopeico). Foi realizada inicialmente a fatoração da solução titulante de sulfato cérico $0,1 \mathrm{M}$, seguida de análise de teor de sulfato ferroso heptaidratado (8).

Para as amostras correspondentes aos comprimidos, foram pesados e pulverizados 20 comprimidos, e transferida a quantidade de pó equivalente a $0,5 \mathrm{~g}$ de sulfato ferroso heptaidratado em relação ao peso médio, para um béquer contendo uma mistura de $20 \mathrm{~mL}$ de ácido sulfúrico $M$ e cerca de $80 \mathrm{~mL}$ de água. Após filtrar e lavar o precipitado até esgotamento, o filtrado e as águas de lavagem foram reunidos, o indicador de ortofenantrolina foi adicionado e a solução-teste foi titulada com a solução sulfato cérico $0,1 M$, de acordo com a FB5 (8).

Para as amostras de solução oral, foi transferido volume equivalente a $625 \mathrm{mg}$ de sulfato ferroso heptaidratado, de acordo com o declarado no rótulo, em frascos contendo $25 \mathrm{~mL}$ de solução de ácido sulfúrico $1 \mathrm{M}$, e $75 \mathrm{~mL}$ de água. Para as amostras de xarope, foi transferido volume equivalente a $125 \mathrm{mg}$ de sulfato ferroso heptaidratado, de acordo com o declarado no rótulo, em 


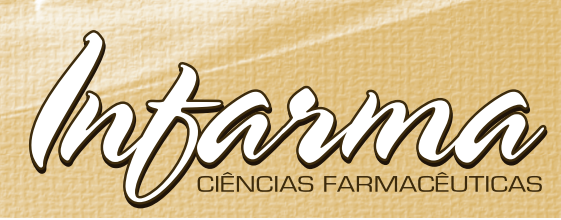

frascos contendo $15 \mathrm{~mL}$ de solução de ácido sulfúrico $1 M$ e $75 \mathrm{~mL}$ de água. Para ambas as amostras, após o indicador de ortofenantrolina ser adicionado, foram realizadas titulações utilizando a solução de sulfato cérico 0,1 M. A água utilizada nas análises foi recentemente fervida e resfriada. Cada $\mathrm{mL}$ de sulfato cérico $0,1 \mathrm{M}$ equivale a $27,80 \mathrm{mg}$ de sulfato ferroso heptaidratado $\left(\mathrm{FeSO}_{4} \cdot 7 \mathrm{H}_{2} \mathrm{O}\right)(8-9)$.

Para o método de titulação direta em amostra de solução oral, foi realizado o cálculo de incerteza por meio do levantamento das fontes de incerteza, a estimativa das incertezas-padrão individuais, o cálculo da incerteza-padrão combinada e da incerteza expandida, em atendimento aos requisitos da ABNT 2005 - Norma Iso IEC 17025 e, integrando o ensaio ao Sistema da Qualidade (11-12).

\section{RESULTADOS E DISCUSSÃO}

As formulações de sulfato ferroso que foram analisadas pelo Centro de Medicamentos, Cosméticos e Saneantes corresponderam a 03 amostras na forma farmacêutica de comprimido, 20 de solução oral e 05 de xarope.

Dentre as 28 amostras coletadas pela Vigilância Sanitária na modalidade análise fiscal, 13 corresponderam aos Programas de Monitoramento da Qualidade de Medicamentos e 15 às queixas técnicas. Do total das amostras analisadas, $16(57,1 \%)$ tiveram resultados satisfatórios e $12(42,9 \%)$ insatisfatórios. Na Figura 1, são aapresentados os resultados insatisfatórios dos ensaios realizados nas amostras.

Com relação ao aspecto, foi detectado vazamento do conteúdo em 05 frascos, oque pode possibilitar contaminação microbiana no produto. Muitas vezes, ocorria o vazamento sobre o rótulo de xaropes e solução oral, dificultando a leitura das informações como o nome do produto, número de lote, data de fabricação e validade. O desvio de qualidade por vazamento de frasco é um possível problema de BPF, provavelmente ocasionado por não haver qualificação do fornecedor de frasco, tampa e lacre, e/ou incompatibilidade com a solução de envase.

Os rótulos devem apresentar informações adequadas para a dispensação, o uso do medicamento, armazenamento correto e rastreamento, desde sua fabricação até o consumo. Não se deve dispensar, nem o paciente adquirir medicamento, com rótulo manchado, borrado, apagado, ou o frasco mal fechado com vazamento, por- que nestas condições, não se tem a confiança e segurança da utilização do medicamento (11). Dentre as amostras analisadas, 02 apresentaram,na declaração do teor sulfato de ferroso e sulfato ferroso heptaidratado, como sendo equivalentes na quantidade de ferro elementar, sendo que estas substâncias têm pesos moleculares diferentes. A falta de informação clara no rótulo compromete a interpretação do resultado da análise de teor, sendo assim, esta não foi realizada. A legislação preconiza que devem estar especificadas no rótulo as quantidades de sulfato ferroso heptaidratado $\left(\mathrm{FeSO}_{4} \cdot 7 \mathrm{H}_{2} \mathrm{O}\right)$ e de ferro elemen$\operatorname{tar}(\mathrm{Fe})$ por unidade posológica. A falta desta informação pode ocasionar erro na administração da dose prescrita e assim uma possível falha terapêutica.

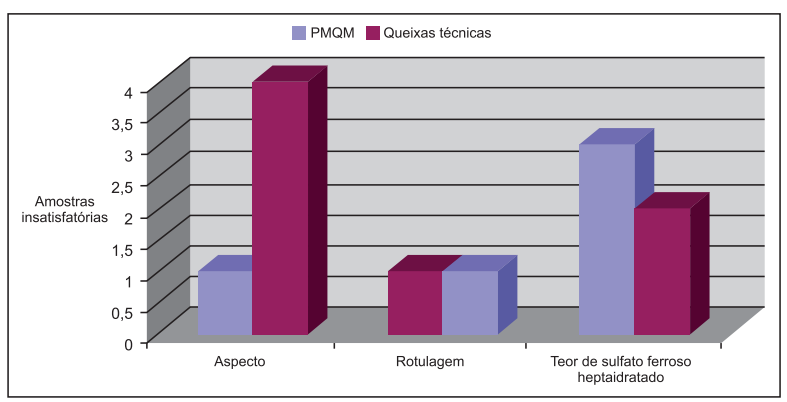

Figura 1 - Resultados insatisfatórios obtidos pelos ensaios das amostras de sulfato ferroso heptaidratado advindas pelo Programa de Monitoramento da Qualidade de Medicamentos (PMQM) ou por Queixas Técnicas

Quanto ao volume, $\mathrm{pH}$ e identificação do sulfato ferroso heptaidratado, as amostras analisadas apresentaram resultados satisfatórios, em conformidade com a Farmacopeia Brasileira (8).

Em 05 amostras constituídas da forma farmacêutica solução oral, foi verificado que o teor de sulfato ferroso heptaidratado apresentava valores menores que a especificação mínima de $94 \%$, conforme estabelecido na Farmacopeia Americana. Esta constatação indica uma evidência de desvio de qualidade e pode ser relacionada à perda de eficácia terapêutica. Destas 05 amostras, 03 pertenciam ao Programa de Monitoramento da Qualidade de Medicamentos e 02 às queixas técnicas identificadas como alteração de cor.

Quanto ao cálculo de incerteza realizada para o método de titulação direta, os componentes de incerteza relacionados com a determinação da concentração da solução molar de sulfato cérico foram: a massa molar de oxalato de sódio, a massa de oxalato de sódio, a pureza do oxalato de sódio; a incerteza da calibração, a resolução e a excentricidade da balança; a incerteza da bureta e sua resolução. 
No que se refere à amostra, os componentes de incerteza da concentração de sulfato ferroso heptaidratado foram a repetitividade na titulação da amostra (uma amostra foi analisada 07 vezes), a incerteza da bureta, o efeito da temperatura, a incerteza da pipeta, a resolução da bureta e a incerteza da solução de sulfato cérico. $O$ resultado da incerteza de $95 \%$ de probabilidade para a solução de sulfato cérico $0,1 \mathrm{M}$ foi de $0,00125 \mathrm{~mol} / \mathrm{L}$ e $\mathrm{K}=2,00$, e para o teor de sulfato ferroso heptaidratado foi $\mathrm{de} \pm 0,2 \mathrm{mg} / \mathrm{mL}$ e $\mathrm{k}=2,0$, sendo o resultado expresso em $131,0 \pm 0,2 \mathrm{mg} / \mathrm{mL}$ para uma das amostras analisadas. A incerteza obtida, embora baixa em relação ao teor, representa a garantia do resultado analítico no relatório de ensaio, quando esta afeta a conformidade com o limite de especificação do produto (12).

Após a emissão dos resultados analíticos por meio do laudo da análise fiscal pelo Laboratório Oficial, este é encaminhado a Vigilância Sanitária, a qual aplica as penalidades cabíveis, em caso de resultados insatisfatórios, e publica em Diário Oficial do Estado de São Paulo-SP. Os hospitais e UBSs são orientados a manter os lotes em questão segregados, caso tenham em estoque. Posteriormente à análise de contraprova, ocorre a desinterdição do lote em caso de resultado satisfatório, ou no recolhimento do mesmo em caso de resultado insatisfatório. Em seguida, ocorre a comunicação ao Centro de Vigilância Sanitária do Estado de São Paulo, e à Agência Nacional de Vigilância Sanitária (Anvisa), bem como nos hospitais e UBSs (13-14).

Programas de Monitoramento da Qualidade de Medicamentos ou a verificação de problemas técnicas nos medicamentos por profissionais da saúde, antes de serem distribuídos aos usuários (pacientes) são de suma importância, por atuarem de forma preventivamente, ou seja, antes de causar agravo ou dano à população.

Diante dos resultados insatisfatórios, $18 \%$ de Programa de Monitoramento da Qualidade de Medicamentos e $25 \%$ de queixas técnicas, nas amostras coletadas pela Vigilância Sanitária, se faz necessário o desenvolvimento de ações sanitárias como as auditorias nas empresas fabricantes, maior rigor na fiscalização pós-comercialização para detectar possíveis desvios de qualidade, assim, garantir a eficácia terapêutica e segurança dos medicamentos nos programas de saúde pública. O fabricante deve garantir a qualidade do produto conforme legislação estabelecida pela Anvisa. No entanto, cabe ao Estado avaliar a qualidade dos produtos sujeitos à vigilância sanitária, contribuindo com a proteção e promoção da saúde da população $(1,15,16)$.

\section{CONCLUSÃO}

A avaliação do medicamento sulfato ferroso heptaidratado em formulações farmacêuticas, mediante o Programa de Monitoramento da Qualidade de Medicamentos mostrou ser um importante instrumento de intervenção proativa do laboratório de saúde pública, ao verificar a qualidade destes. Os resultados insatisfatórios verificados por inconformidade nas embalagens (vazamento das formulações líquidas), rótulo (não constava informação obrigatória da quantidade de sulfato ferroso heptaidratado e de ferro elementar) e teor do ativo (inferior ao declarado na rotulagem) tornaram evidente a deficiência no cumprimento das BPF. Desta forma, se torna necessária a continuidade deste Programa de Monitoramento da Qualidade de Medicamentos a fim de garantir o acesso aos medicamentos com qualidade e segurança à população.

\section{AGRADECIMENTOS}

Os autores agradecem à colaboração das Pesquisadoras científicas Maria Cristina Santa Bárbara e Márcia R. P. A. Mello na análise estatística dos dados e da Farmacêutica Rita Cristina Agostinho Guardia na contribuição da análise das amostras

\section{REFERÊNCIAS}

1. Anvisa. Agência Nacional de Vigilância Sanitária. Novas regras para rotulagem de medicamentos. Disponível em: <http://websphere.anvisa.gov.br/wps/content/ Anvisa+Portal/Anvisa/Setor+Regulado/Como+Fazer/ Bulas + e+Rotulos + de + Medicamentos/Rotulos/Novas $+r$ egras + para + rotulagem + de + medicamentos $>$. Acesso em 29 de agosto de 2014.

2. BRASIL. Ministério da Saúde. Portaria GM No 3.916 , de 30 de outubro de 1998. Dispõe sobre a Política Nacional de Medicamentos. Diário Oficial da União. $\mathrm{N}^{\mathrm{o}}$ 215-E Seção 1, p. 18 a 22, de 10 de novembro de 1998.

3. BRASIL. Agência Nacional de Vigilância Sanitária. Resolução RDC n⿳3 338, de 06 de maio de 2004. Aprova a Política Nacional de Assistência Farmacêutica. Diário Oficial da União, Seção 1, p. 52 de 20 de maio de 2004. 


\section{Arizama}

4. WHO. World Health Organization. Essencial Medicines Selection. Essential medicines selection. Disponível em: $<$ http://www.who.int/selection_medicines/list/en/>. Acesso em 07 de junho de 2014.

5. RENAME. Relação Nacional de Medicamentos Essenciais. Anexo I - Relação Nacional de Medicamentos do Componente Básico da Assistência Farmacêutica. Disponível: <http://portalsaude.saude.gov. br/images/pdf/2013/outubro/21/rename-anexos-versao-08-08-2013.pdf $>$. Acesso em 12 de novembro de 2014.

6. Rang HP, Dale MM, Ritter JM, Flower RJ, Henderson G. Rang \& Dale Farmacologia. $7^{\mathrm{a}}$ ed. Rio de Janeiro: Elsevier. 2012.

7. British Pharmacopoeia. Londres: The Stationery Office. 2012.

8. Farmacopeia Brasileira. 5 ed. volume I. Brasília: Agência Nacional de Vigilância Sanitária. 2010.

9. United States Pharmacopeia. 39 ed. Rockville: United States Pharmacopeial Convention. 2016.

10. Harris DC. Análise Química Quantitativa. Tradução de José Alberto Portela Bonapace e Oswaldo Esteves Barcia. $6^{\text {a }}$ ed. Rio de Janeiro: LTC. 2005.

11. EURACHEM/CITAC Guide. Measurement uncertainty arising from sampling: a guide to methods and approaches Eurachem. $1^{\text {st }}$ ed. 2007.
12. ABNT. Associação Brasileira de Normas Técnicas. NBR ISO/IEC 17025. Requisitos gerais para a competência de laboratórios de ensaio e calibração. Rio de Janeiro: ABNT, 2005.

13. BRASIL. Lei ${ }^{\circ} 6.437$, de 20 de agosto de 1977. Configura infrações à legislação sanitária federal, estabelece as sanções respectivas, e dá outras providências. Diário Oficial da União, Seção 1, p. 11145 de 24 de agosto de 1977.

14. SÃO PAULO. Prefeitura Municipal de São Paulo. Lei Municipal $n^{\circ} 13.725$, de 9 de janeiro de 2004. Institui o Código Sanitário do Município de São PauloDiário Oficial do Município. 10 janeiro 2004. [lei na internet]. Disponível: http://www.prefeitura.sp.gov.br/cidade/secretarias/upload/LeiMunicipal_2004_13725_1255012330. pdf. Acesso em 30 de julho de $20 \overline{1} 4$.

15. Graff S. Vigilância Pós-Comercialização: aprendendo a atender o consumidor com reação adversa. $1^{a}$. ed. São Paulo: Scortecci, 2012.

16. Anvisa. Agência Nacional de Vigilância Sanitária. O que devemos saber sobre medicamentos. Disponível em: $<$ http://portal.anvisa.gov.br/wps/wcm/connect/92aa8c0 0474586ea9089d43fbc4c6735/Cartilha\%2BBAIXA \% 2Brevis\%C3\%A3o\%2B24_08.pdf?MOD=AJPERES>. Acesso em 12 de novembro de 2014. 